\title{
NEW ACHILLEA-FEEDING SPECIES OF THE APHID GENUS UROLEUCON (HEMIPTERA: APHIDIDAE) FROM BULGARIA
}

\author{
Mariusz KantURSKI \\ Zoology Research Team, Institute of Biology, Biotechnology and Environmental Protection, \\ Faculty of Natural Sciences, University of Silesia in Katowice \\ ul. Bankowa 9, 40-007 Katowice, Poland \\ E-mail: mariusz.kanturski@us.edu.pl; https://orcid.org/0000-0002-1674-1028
}

\begin{abstract}
An apterous viviparous female of a new aphid species Uroleucon (Uroleucon) bulgaricum sp. $\mathbf{n}$. is described and compared with the similar species U. (Uroleucon) achilleae (Koch, 1865). The new species was collected by the late J. Holman in the Blagoevgrad region (SE Bulgaria), where it is associated with Achillea coarctata Poiret in Lam. (Asteraceae). The similarities and differences between other Achillea-feeding Uroleucon species are discussed. A morphological key to the species of the subgenus Uroleucon Mordvilko, 1914 in Bulgaria is presented. A modified key to the Achillea-feeding Uroleucon aphids of Blackman and Eastop is also provided.
\end{abstract}

Key words: Uroleucon, Hemiptera, Aphididae, Achillea, aphids, Blagoevgrad, Macrosiphini, taxonomy.

\section{INTRODUCTION}

The genus Uroleucon Mordvilko, 1914 (Hemiptera, Aphididae: Aphidinae) is one of the most speciose within the tribe Macrosiphini Wilson, 1910 (Favret 2020, Blackman 2010). The genus, with 247 valid species is divided into six subgenera of which Lambersius Olive, 1965 (58 species); Uroleucon Mordvilko, 1914 (122 species) and Uromelan Mordvilko, 1914 (62 species) are the most species-rich. The subgenera Belochilum Börner, 1932; Divium Pashtshenko, 2000 and Satula Olive, 1963 are considered monotypic. Representatives of this genus are particularly characterised by a long terminal process of the last antennal segment, the presence of secondary rhinaria on ANT III in apterous viviparous females, a more or less tubular or tapering, long siphunculi with a subapical zone with polygonal reticulation and often differently developed scleroites at the setal bases (HeIE 1995). They are relatively medium-sized to large, shiny (from red to bronze coloured), they often feed on the upper parts of plants and are not visited by ants (BLACKMAN 2010).

Out of the 305 valid Urolecuon species (FAVRET 2020), only six are associated with the plant genus Achillea (Asteraceae): U. (Uroleucon) achilleae (Koch, 1855) U. (U.) alaskense Robinson, 1985, U. (U.) ambrosiae (Thomas, 1878), $U$. (U.) astronomus (Hille Ris Lambers, 1962), U. (U.) ptarmicae (Bozhko, 1959) and $U$. (Lambersius) stoetzelae Robinson, 1988. Of those, only $U$. achilleae and $U$. 
ptarmicae are known from Europe (Blackman \& Eastop 2006, 2020). From Bulgaria, 21 Uroleucon species have been described and recorded to date of which 13 are in the nominotypical subgenus (NiETo NAFría 2013, KANTURSKI \& BARJADZE 2020). During an examination of the aphid collection in the Aphidoidea collection of the Biology Centre of the Czech Academy of Sciences, Institute of Entomology, České Budějovice (IECA), slides of Uroleucon individuals that had been labelled with the manuscript name "Uroleucon bulgaricum" by the late Jaroslav Holman were studied. The specimens were collected from Achillea coarctata Poiret in Lam. (Asteraceae) in Southeastern Bulgaria. After these were compared with the most similar Uroleucon representatives, it appears to be a new European species, and its description is the primary goal of this paper.

\section{MATERIAL AND METHODS}

The specimens were examined using a Leica DM 3000 LED light microscope and photographed using a Leica MC 190 HD camera using a differential interference contrast. The measurements were taken according to ILHARco and van HARTEN (1987). All of the measurements are given in millimetres. The current host plant names are given according to The Plant List (2013). The following abbreviations are used: ABD TERG: abdominal tergite; ANT: antennae or their lengths; ANT I-VI: antennal segments I, II, III, IV, V, VI or their lengths (ratios between antennal segments are simply given as e.g. 'VI: III'); BASE: basal part of last antennal segment or its length; BD III: basal articular diameter of ANT III; BL: body length (from the anterior border of the head to the end of cauda); III FEMORA: hind femora length; HW: greatest head width across the compound eyes; HT I: first segment of the hind tarsus; HT II: second segment of the hind tarsus or its length; LS ANT III: length of the longest setae of ANT III; PT: processus terminalis of the last antennal segment or its length; SIPH: siphunculus or its length; III TIBIAE: hind tibiae length; URS: ultimate segments of the rostrum (IV $+\mathrm{V}$ ) or their lengths. In the case of a series of single slides with a single specimen with the same collection data for the examined material sections, all of them present the same data as the full previous slide to avoid repetition.

The type material is deposited in the IECA - the Biology Centre of the Czech Academy of Sciences, Institute of Entomology, České Budějovice (Czech Republic) and the DZUS - Zoology Research Team, University of Silesia in Katowice Hemiptera Collection, Katowice (Poland).

The material of Uroleucon achilleae that was examined: three apterous viviparous females, Bulgaria, reg. Vidim, Belogradčik, 04.06.1990, Achillea crithmifolia Waldst. \& Kit., J. Holman leg., 21972, IECA; two apterous viviparous females, Salaš, 03.06.1990, J. Holman leg., 21949 (apt 1-2), IECA; one apterous viviparous female, Czech Republic, Kraj Vysočina, Sněžné, 17.08.1973, Achillea millefolium L., J. Holman leg., 14474, IECA; two apterous viviparous females, Hungary, Gyöngyös, Mátrafüred, 23.06.1964, A. millefolium, H. Szelegiewicz leg., 2284, R4117, ZMPA; one apterous viviparous female, Poland, Pomeranian Voivodeship, Władysławowo, 17.06.1966, A. millefolium, H. Szelegiewicz leg., 3139, R4115, ZMPA (Museum of Zoology, Polish Academy of Sciences, Warsaw, Poland); two apterous viviparous females, Masovian Voivodeship, Warszawa-Bielany, 08.07.1956, A. 
millefolium, H. Szelegiewicz leg., 285, R4120, ZMPA; four apterous viviparous females, Stamirowice near Grójec, 18.08.1961, A. millefolium, H. Szelegiewicz leg., 1673, R4116 (ZMPA); one apterous viviparous female, Podkarpackie Voivodeship, Rzeszów, 23.06.1965, A. millefolium, S. Huculak leg., R4121, ZMPA; one apterous viviparous female, R4345, ZMPA; two apterous viviparous females, Slovakia, Region Trnava, Buková, 29.07.1982, A. millefolium, J. Holman leg., 18100, IECA;

\section{TAXONOMY}

Aphididae Latreille, 1802

Aphidinae Latreille, 1802

Macrosiphini Wilson, 1910

Uroleucon Mordvilko, 1914

\section{Uroleucon (Uroleucon) bulgaricum sp. n.}

$$
\text { (Figs 1-4) }
$$

Material examined: Holotype. Apterous viviparous female, Bulgaria, reg. Blagoevgrad, Elešnica near Rila, 09.09.1988, Achillea coarctata, J. Holman leg., 20519A (apt 8), IECA.

Paratypes. Apterous viviparous female, other data same as in holotype, 20519A (apt 9), IECA; two apterous viviparous females, 09.09.1090, other data same as in holotype, 20519A (apt 27-28), IECA; two apterous viviparous females, 09.09.1090, other data same as in holotype, 20519A (apt 35-36), IECA; two apterous viviparous females, 09.09.1090, other data same as in holotype, 20519A (apt 53-54), IECA; two apterous viviparous females, 09.09.1090, other data same as in holotype, 20519A (apt 37-38), DZUS; two apterous viviparous females, Rilski Manastir, 10.10.1988, A. coarctata, J. Holman leg., 20530 (apt 5-6), IECA; two apterous viviparous females, other data same as in 20530 (apt 21-22), IECA.

Apterous viviparous female - description ( $n=14$ ) (Figs 1-4, Table 1). Colour in life: unknown. Pigmentation on slide: head sclerotised, light brown; ANT I-II brown; ANT yellow with darker apical end of ANT III-IV, brown distal half of ANT V; pronotum and mesonotum usually with yellow sclerotisation; Femora of legs yellow with only the apices slightly dusky; tibiae yellow with dark distal parts, tarsi dark brown; abdomen yellow with brown sclerites and scleroites; SIPH uniformly dark brown, cauda yellow (Fig. 1a). HW 0.14-0.15 $\times$ ANT. Head with long, rigid and pointed setae, 0.070-0.100 mm long. ANT tubercles each with 2-3 setae on internal angles. ANT 1.33-1.60 × BL. ANT III with 9-12 slightly protuberant, rounded, different-sized secondary rhinaria with well-developed sclerotised rims (Fig. 2a, b), ANT IV longer than ANT V. PT 5.41-6.31 × BASE. Other antennal ratios: VI:III 1.44-1.67, V:III 0.80-0.84, IV:III 0.86-0.92, PT:III 1.24-1.54, PT:IV 1.42-1.53, PT:V 1.50-1.67. ANT chaetotaxy: ANT have thick, rigid setae with slightly blunt or narrow capitate apices. ANT III setae 0.02-0.06 mm long, LS ANT III 1.33-1.71 × BD III. ANT I with 7-8, ANT II with 4-5, ANT III with 15-18, ANT IV with 13-14, ANT V with 9-11 setae. ANT VI with 3 basal, 4 apical and 4-6 setae along the PT. Rostrum reaching hind coxae. URS 0.23-0.30 × ANT III, 0.16-0.18 × ANT VI, 0.18-0.21 × PT, 1.11-1.21 × BASE and 1.40-1.66 × HT II with 4-5 fine, pointed accessory setae (Fig. 2c). Mesosternal furca fused, wide, without stem (Fig. 3a). III FEMORA have medium-long to long, stiff, rigid and pointed setae, 
0.020-0.065 mm long. Setae on III TIBIAE with rigid, medium-long to long and pointed setae, $0.025-0.075 \mathrm{~mm}$ long. HT I with 5:5:5 setae, HT II 0.15-0.18 $\times$ ANT III, $0.10-0.12 \times$ ANT VI, $0.12-0.14 \times$ PT and 0.70-0.81 $\times$ BASE. Abdomen membranous without marginal tuber-

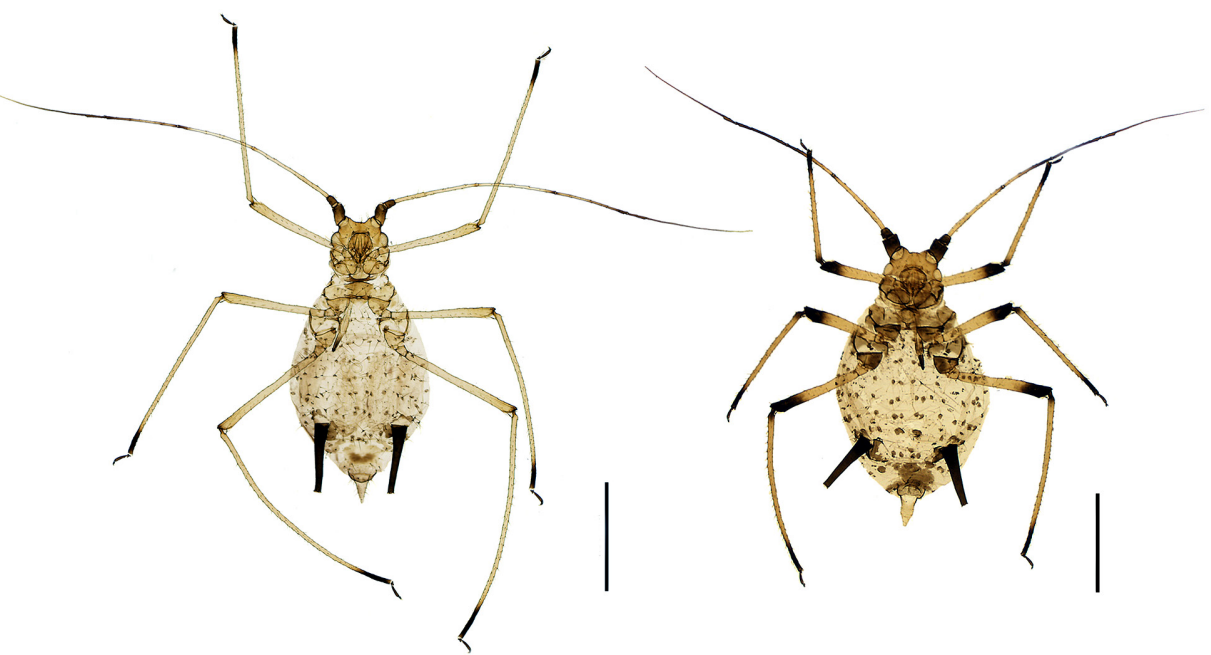

Fig. 1. Comparison of the general view of the holotype of a = Uroleucon bulgaricum sp. $\mathrm{n}$. and $\mathrm{b}=U$. achilleae (Koch). Scale bar: $1.00 \mathrm{~mm}$

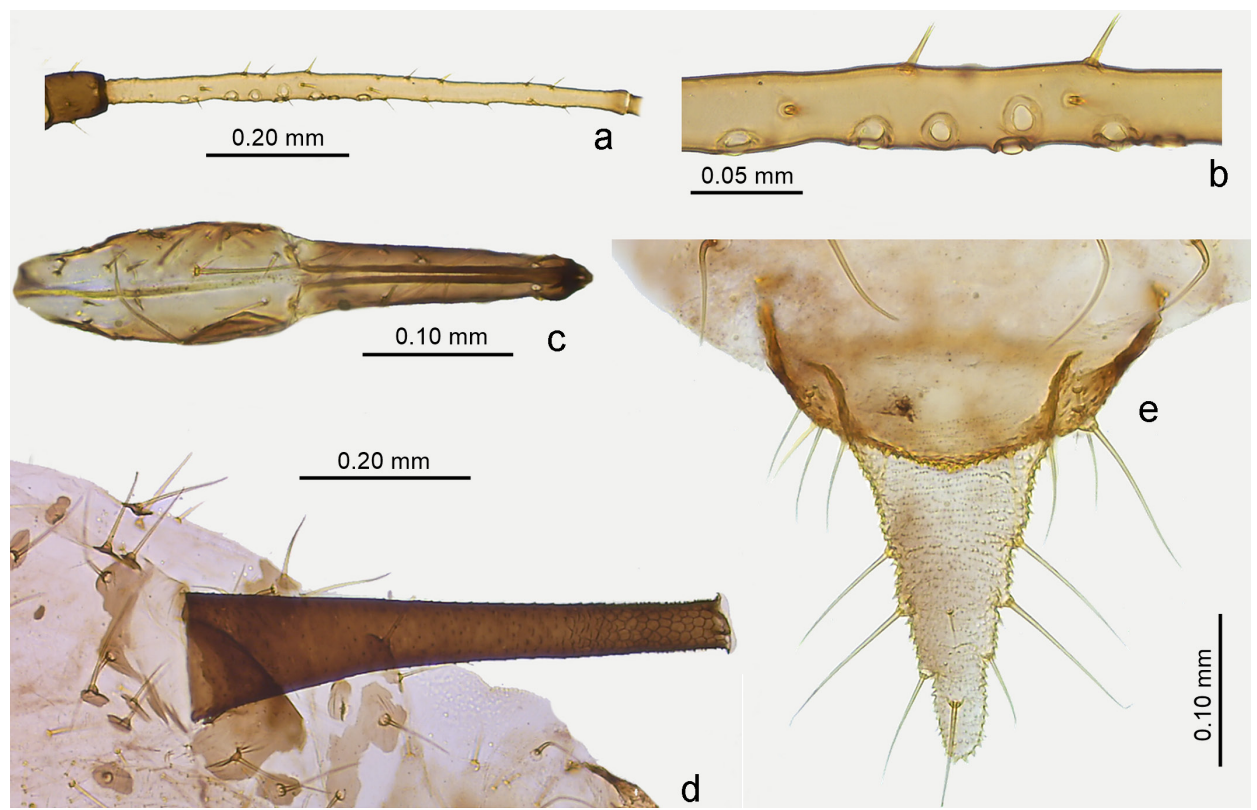

Fig. 2. Uroleucon bulgaricum sp. $n$. morphological characters: $a=$ antennal segment III, $b=$ antennal segment III secondary rhinaria structure, $\mathrm{c}=$ ultimate rostral segments, $\mathrm{d}=\mathrm{SIPH}, \mathrm{e}=$ cauda 
cles with long and rigid setae with pointed apices, $0.080-0.130 \mathrm{~mm}$ long on ABD TERG I-V and $0.085-0.130 \mathrm{~mm}$ long on ABD TERG VI-VIII. ABD VIII with 4-6 setae without sclerotised bar. Setae on abdomen arising from well-visible, rounded or slightly irregular scleroites, larger than setae bases (Fig. 4a, c). SIPH tubular, tapering with a distinct zone of subapical reticulation, well-developed antesiphuncular and postsiphuncular sclerites and small flange (Fig. 3d). Reticulated zone 0.22-0.30 × SIPH. SIPH 2.29-2.71 × cauda, 0.22-0.29 $\times$ BL and 0.76-0.87 $\times$ ANT III. Genital plate with 2-4 long anterior, 0-2 median and 7-13 shorter posterior setae. Cauda triangular, 1.56-1.75 $\times$ its width at base and $0.09-0.10 \times \mathrm{BL}$ with 7-9 long, thick and pointed setae (Fig. 2e).

Diagnosis. The new species is most similar to Uroleucon achilleae (Fig. 1b) because of the similar number of secondary rhinaria on ANT III, siphunculi and cauda ratios, the cauda length to width and the number of caudal setae. Additionally, the long, thick and rigid setae that arise from well-developed scleroites are both species-shared characters.

However, the apterous viviparous females of $U$. bulgaricum differ from those of $U$. achilleae in several apparent features such as:
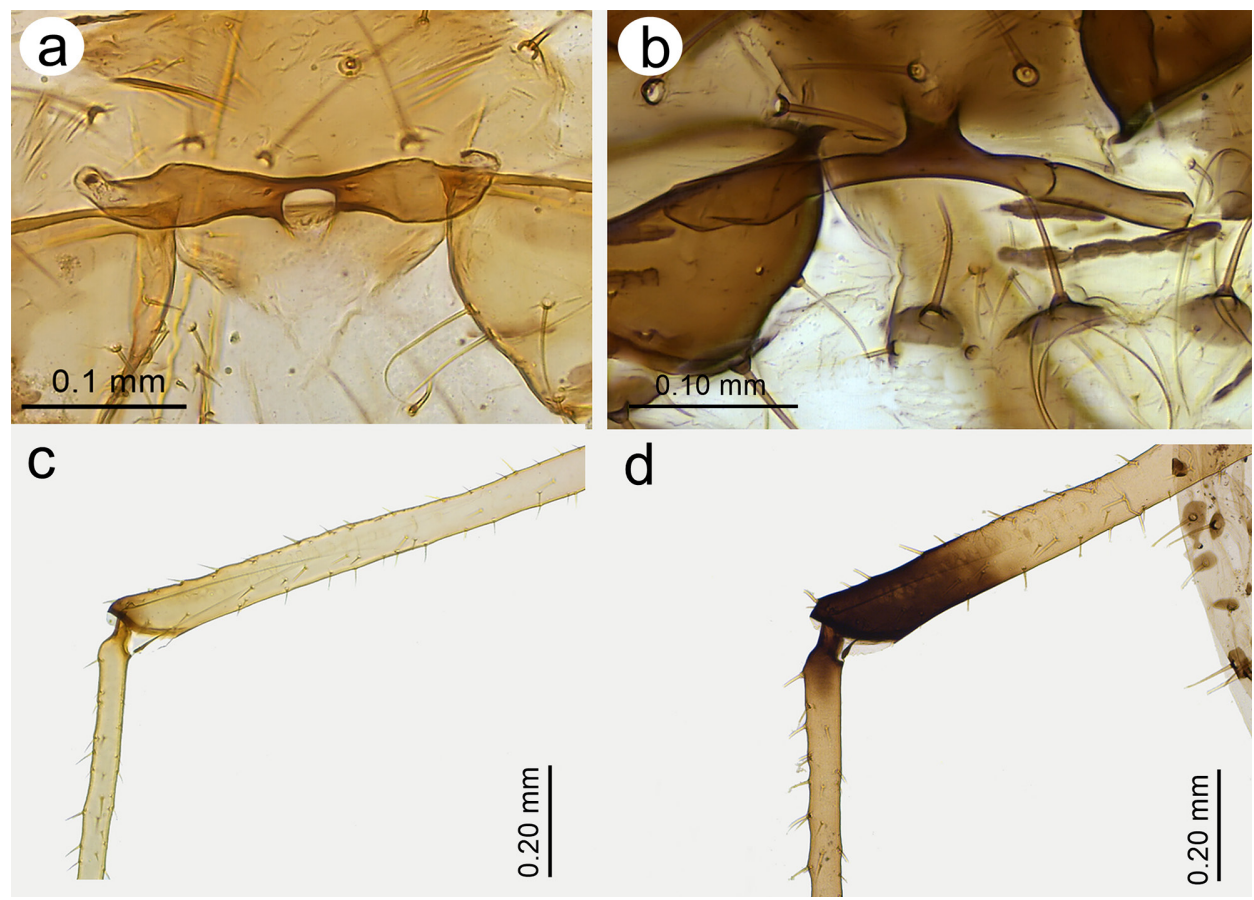

Fig. 3. Differences between Uroleucon bulgaricum and U. achilleae: $\mathrm{a}=$ mesosternal furca of $U$. bulgaricum without a stem, $\mathrm{b}=$ mesosternal furca of $U$. achilleae with a well-developed stem, c = pigmentation of the distal part of the femur and proximal part of the tibia of $U$. bulgaricum, $\mathrm{d}$ = pigmentation of the distal part of the femur and the proximal part of the tibia of $U$. achilleae 
Table 1. Measurements (in $\mathrm{mm}$ ) of an apterous viviparous female of Uroleucon bulgaricum.

\begin{tabular}{lc}
\hline Character & $\begin{array}{c}\text { Apterous } \\
\text { viviparous female }\end{array}$ \\
\hline BL & $1.95-2.70$ \\
HW & $0.46-0.52$ \\
ANT & $3.12-3.62$ \\
ANT III & $0.65-0.81$ \\
ANT IV & $0.60-0.71$ \\
ANT V & $0.55-0.67$ \\
ANT VI & $1.09-1.17$ \\
BASE & $0.16-0.17$ \\
PT & $0.92-1.01$ \\
URS & $0.19-0.20$ \\
FEMORA III & $0.95-1.17$ \\
TIBIAE III & $1.95-2.27$ \\
HT II & $0.12-0.13$ \\
SIPH & $0.57-0.67$ \\
CAUDA & $0.21-0.27$ \\
\hline
\end{tabular}

- Mesosternal furca without a stem (mesosternal furca with a well-developed stem in $U$. achilleae) (Figs $3 a, b$ ).

- $\quad$ Femora of legs are only slightly dusky at the very apical tips (femora of legs brown to dark brown on about $1 / 4$ of their distal length in $U$. achilleae) (Figs $3 c, d$ ).

- Proximal part of the tibiae of the legs yellow (proximal part of the tibiae brown to dark brown in U. achilleae).

- $\quad$ ANT pale with distal ends of ANT IV and V brown and brown ANT VI (ANT brown to dark brown with only basal and central part of ANT III paler in U. achilleae). - Antesiphuncular sclerites present (antesiphuncular sclerites absent in most representatives of $U$. achilleae as well as according to Blackman (2010) (Figs 4a, b).

- Dorsal setae pointed (dorsal setae blunt or capitate $U$. achilleae) (Figs $4 c, d$ ).

- $\quad$ ABD VIII not sclerotised (ABD VIII with a solid sclerotic bar in U. achilleae). - $\quad$ Lower ratio of HT II:BASE, 0.70-0.81 (0.90-1.04 in U. achilleae).

Etymology. The name of the species is derived from Bulgaria where it was collected. I have the pleasure to follow the naming of this species according to J. Holman's suggestions and notes on the slides.

Host plant and biology. The species feeds on Achillea coarctata Poir. from the family Asteraceae, but nothing is known about the place where it feeds. Alate viviparous females and sexual morphs are as yet unknown.

\section{Taxonomical comments}

In the Palaearctic, only two species of the genus Uroleucon are known to feed on Achillea - Uroleucon achilleae, which is a common species in most countries, and U. ptarmicae, which to date is only known from Ukraine from where it was described (Holman 2009, Bоzнко 1976). The remaining species including $U$. stoetzelae from the subgenus Lambersius are known from North America. Of the last one, $U$. bulgaricum sp. n., differs first of all in subgeneric 
differences such as its uniformly dark pigmented siphunculi (pale basally in Lambersius), next by fewer accessory setae on the URS and the lack of marginal tubercles on the abdomen (RoBInson 1988). In reference to the remaining species with uniformly dark siphunculi, the new species ranks as entirely independent with its features but is similar in some of its features to $U$. achilleae/U. ptarmicae, which differ from the group of the American species $U$. astronomus/U. alaskense/U. ambrosiae. According to the Achillea-feeding key to aphids of BLACKMAN and EAstop (2020), the group U. achilleae/U. ptarmicae can be distinguished by the presence of antesiphuncular (presiphuncular) sclerites on the abdomen and a high ratio of the SIPH:cauda, which is more than 1.6. Uroleucon bulgaricum sp. n. fits into the first group by its abdomen, which has rather well-visible antesiphuncular sclerites as well as its SIPH:cauda ratio. The two species can be distinguished from $U$. ptarmicae first of all by its much shorter cauda (less than $0.35 \mathrm{~mm}$ ), shorter ANT III (about 0.91 in $U$.
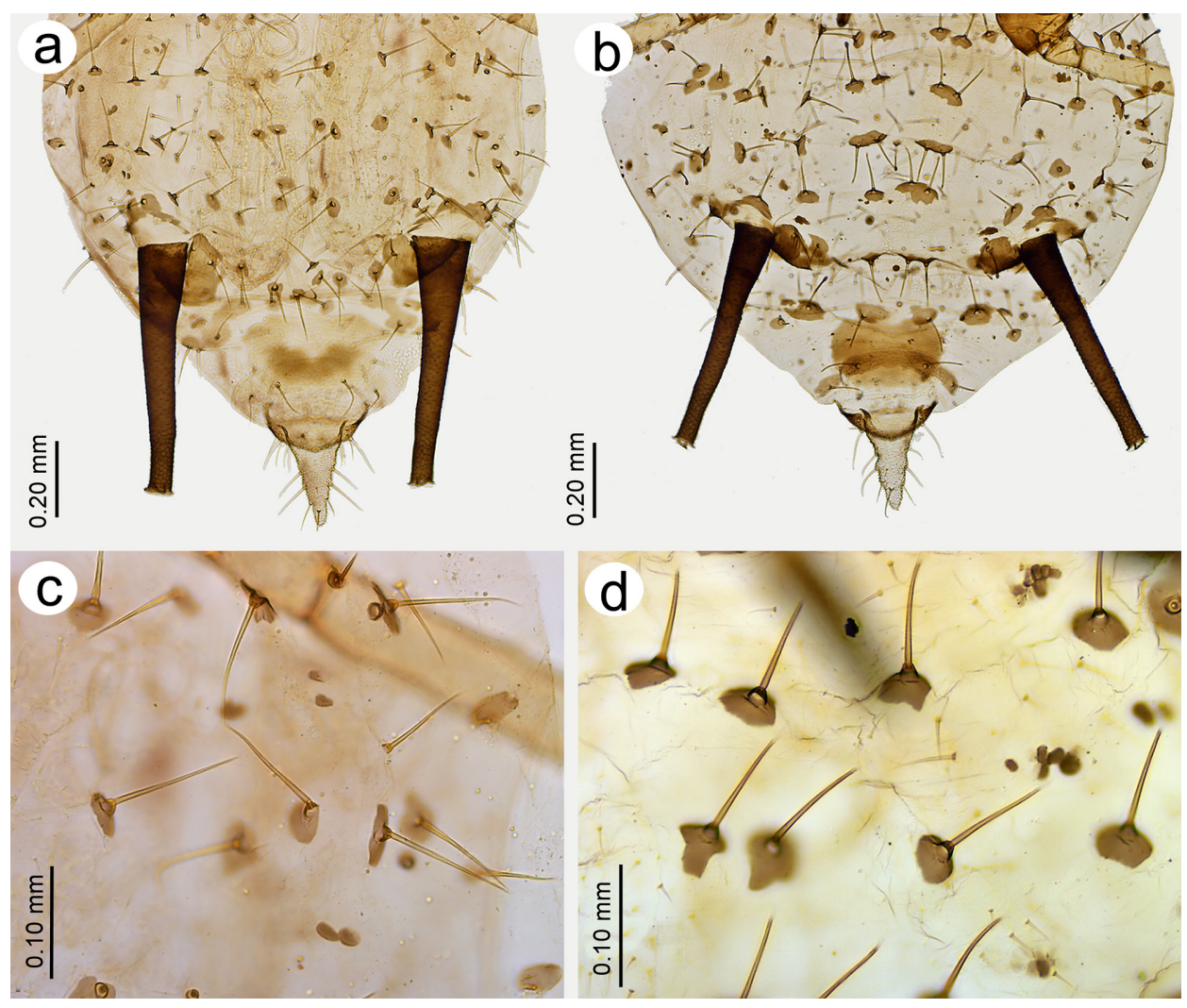

Fig. 4. Differences between Uroleucon bulgaricum and $U$. achilleae: $\mathrm{a}=$ abdomen of $U$. bulgaricum, $\mathrm{b}=$ abdomen of $U$. achilleae, $\mathrm{c}=$ abdominal setae of $U$. bulgaricum, $\mathrm{d}=$ abdominal setae of $U$. achilleae 
ptarmicae) and by the smaller number of secondary rhinaria on ANT III (not more than 26 rather than more than 30 in U. ptarmicae) (Bozнко 1976). The new species clearly differs from $U$. achilleae by all the differences given in the diagnosis section, especially by the pigmentation of the antennae and legs, mesosternal furca without a stem and pointed dorsal setae.
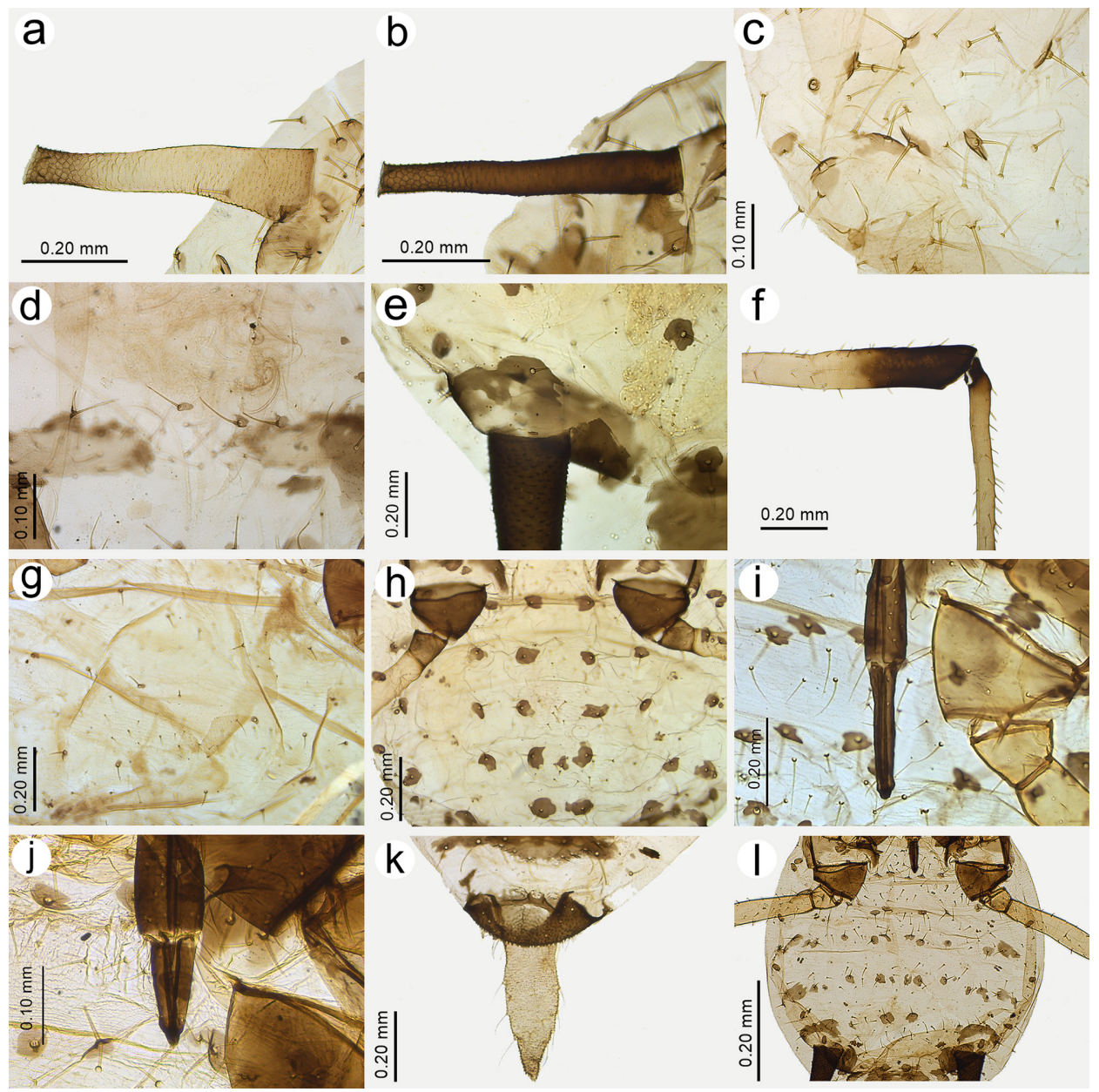

Fig. 5. Main key morphological features of species of the subgenus Uroleucon in Bulgaria: $\mathrm{a}=$ siphunculi of $U$. tussilaginis with a middle section pale, $\mathrm{b}=$ dusky siphunculi of $U$. sonchi, $\mathrm{c}=$ dorsal abdominal scleroites of $U$. tanaceti, $\mathrm{d}=$ dorsal abdominal scleroites of $U$. tussilaginis, $\mathrm{e}=$ antesiphuncular sclerite on abdomen of $U$. sonchi, $\mathrm{f}=$ pigmentation of hind femur and tibiae of $U$. picridis, $\mathrm{g}=$ dorsal abdominal scleroites of $U$. sonchi, $\mathrm{h}=\mathrm{dorsal}$ abdominal scleroites of $U$. cichorii, $\mathrm{i}=$ ultimate rostral segments of $U$. picridis, $\mathrm{j}=$ ultimate rostral segments of $U$. obscurum, $\mathrm{k}=$ cauda of $U$. jaceicola, $1=$ dorsal abdominal scleroites of $U$. hypochoeridis 
Additionally, the new species differs from $U$. achilleae because of its longer URS and shorter cauda. It should be noted here that on the other hand, HeIE (1995) and BLACKMAN (2010) placed $U$. achilleae into the group together within Uroleucon species, which have no antesiphuncular sclerites. In fact, during an examination of the material for comparison, specimens of $U$. achilleae with and without antesiphuncular sclerites were observed and examined. In the author's opinion, this is not an error in the key of the Achillea-feeding aphids of Blackman and Eastop (2020), and two explanations are possible. Most probably, in many cases of some specimens of $U$. achilleae, the scleroites at the setal bases often fuse into larger ones (Fig. $4 b$ ). When this fusion occurs in front of the siphunculi, they might be treated or mistaken as poorly developed or vestigial antesiphuncular sclerites, especially in a flat slide-mounted specimen. The second possibility is that perhaps two or more taxa are included in the combination of common features for $U$. achilleae and a future molecular study would solve such question.

Taking into account the basic morphological features of many European species of the nominotypical subgenus Uroleucon, U. bulgaricum sp. n., which has a uniformly dark pigmented siphunculi; well-developed antesiphuncular sclerites; well-visible, dark scleroites at the setal bases and a high ratio of URS:HT II, is similar and can be compared with U. leontodontis (Hille Ris Lambers, 1939) and U. picridis (Fabricius, 1775) (Heie 1995, Blackman 2010). The new species can be easily distinguished from both species by the pigmentation of legs (in this character the new species also differs from most species, which have dark pigmented distal parts of femora and proximal parts of the tibiae), the lack of marginal tubercles and fewer accessory setae on the URS.

Key to Bulgarian species of the nominotypical subgenus Uroleucon

The key partially based on Szelegiewicz 1962, Holman 1981, Heie 1995, BLACKMAN 2010, and the material of the European Uroleucon slides that are deposited in the IECA and ZMPA. According to KANTURSKI and BARJADZE (2020), $U$. bielawskii and $U$. mulgedii belong to the subgenus Lambersius.

1 SIPH clearly pale in the middle (Fig. 5a)

- $\quad$ SIPH uniformly dusky to dark (Fig. 5b)

2 Scleroites at setal bases dark, much larger than setae bases (Fig. 5c)

U. tanaceti (Linnaeus, 1758)

- Scleroites at setal bases indistinct, pale, not much larger than setae bases (Fig. 5d)

U. tussilaginis (Walker, 1850) 
3 Antesiphuncular sclerites present (Fig. 5e) 4

- Antesiphuncular sclerites absent 11

4 Scleroites at setal bases indistinct, pale, not larger than setae bases (Fig. $5 g)$

U. sonchi (Linnaeus, 1767)

- Scleroites at setal bases dark, larger than the setae bases (Fig. 5h) 5

5 Distal halves of femora and proximal parts tibiae pale or yellow. Cauda triangular (Figs $3 e, c$ ) U. bulgaricum sp. $\mathrm{n}$.

- Distal halves of femora and proximal parts tibiae pale or dark. Cauda tongue-shaped (Figs $3 d, 5 f$ )

6 URS 1.45-1.57 × HT II, long and slender (Fig. 5i)

U. picridis (Fabricius, 1775)

- $\quad$ URS 0.84-1.35 × HT II, not long and slender (Fig. 5j) 7

7 URS $0.84-1.08 \times$ HT II (rarely more than 1.05). Marginal sclerites larger than sclerites and scleroites in spinal and pleural area (Fig. 5l)

U. hypochoeridis (Fabricius, 1779)

- $\quad$ URS 1.04-1.33 × HT II (rarely more than 1.10). Marginal sclerites not larger than sclerites and scleroites in spinal and pleural area

8 Hind tibiae dark

U. cichorii

- Hind tibiae with distinct pale section

9 HT I with 3-3-3 setae

U. pilosellae (Börner, 1933)

- HT I with 5-5-5 setae

10 ANT III with 13-54 secondary rhinaria

U. obscurum (Koch, 1855)

- $\quad$ ANT III with 63-74 secondary rhinaria (Bulgarian specimens)

U. chondrillae (Nevsky, 1929)

11 URS very long, 2.30-2.60 × HT II with 30-36 accessory setae

U. bifrontis (Passerini, 1879)

- $\quad$ URS much shorter, $0.76-2.00 \times$ HT II with not more than ten accessory setae

12 URS $0.76-0.87 \times$ HT II with 8-10 accessory setae U. murale (Buckton, 1876)

- $\quad$ URS 1.10-2.00 × HT II with 5-6 accessory setae 
13 Cauda triangular, not longer than $2.0 \times$ its basal width. SIPH less than $0.33 \times \mathrm{BL}$ U. achilleae (Koch, 1855)

- Cauda tongue shaped (Fig. 5k), longer than $2.0 \times$ its basal width. SIPH more than $0.33 \times \mathrm{BL}$ U. jaceicola (Hille Ris Lambers, 1939)

\author{
BLACKMAN and EAstop (2020) modified key \\ to Achillea-feeding Uroleucon (from couplet 36)
}

36 SIPH 1.7-2.9 × cauda. Presiphuncular sclerites present, vestigial or absent.

- $\quad$ If SIPH are more than $1.6 \times$ cauda, then $\mathrm{R} \mathrm{IV+V}$ bears at least 17 accessory hairs. Presiphuncular sclerites absent.

37 Cauda, less than $0.35 \mathrm{~mm}$ long and less than twice its basal width. ANT III with 7-24 rhinaria

- Cauda more than $0.4 \mathrm{~mm}$ long and more than twice its basal width. ANT III with 30-36 rhinaria

U. ptarmicae

38 Femora of legs with dark distal halves. Mesosternal furca with well-developed stem, dorsal setae blunt or slightly capitate

U. achilleae

- Femora of legs yellow with only the apices slightly dusky. Mesosternal furca without stem, dorsal setae pointed

U. bulgaricum

39 R IV + V bearing 17-24 accessory hairs

U. astronomus

- $\quad$ RIV $+\mathrm{V}$ with ten or fewer hairs

40 Marginal tubercles (MTu) well developed and evident on at least ABD TERG 2-5. SIPH 1.0-1.2 × cauda and 0.21-0.26 × BL

U. alaskense

- MTu usually absent. SIPH 1.2-1.5 × cauda and 0.25-0.30 × BL U. ambrosiae

Acknowledgements - I am very grateful to Aleš Bezděk (Biology Centre of the Czech Academy of Sciences, České Budějovice, Czech Republic) for his kind assistance and support during my visits to the collection as well as for the loan of the many slides. I gratefully acknowledge the Scholarship for Outstanding Young Scientists from the Ministry of Science and Higher Education of Poland (1165/E-340/STYP/12/17). I thank two anonymous reviewers for improving the manuscript. 


\section{REFERENCES}

Blackman, R. L. (2010): Aphids - Aphidina (Macrosiphini). Handbooks for the identification of British insects 2(7), 414 pp.

Blackman, R. L. \& Eastop, V. F. (2006): Aphids on the world's herbaceous plants and shrubs. John Wiley \& Sons, London, 1439 pp.

Blackman, R. L. \& EAstop, V. F. (2020): Aphids of the world's plants: An online identification and information guide. Available from: http://www.aphidsonworldsplants.info [accessed 15 September 2020]

Bоzнко, M. P. (1976): [New and little-known aphids from the southern European regions of the USSR.] - Entomologicheskoe Obozrenie 55: 863-874. (English translation in Entomological Review 55: 93-101.

FAvret, C. (2020): Aphid species file. Version 5.0/5.0. Available from: http://Aphid.SpeciesFile.org [accessed 15 September 2020]

HeIE, O. E. (1995): The Aphidoidea (Hemiptera) of Fennoscandia and Denmark. VI. Family Aphididae: Part 3 of tribe Macrosiphini of subfamily Aphidinae, and family Lachnidae. - Fauna Entomologica Scandinavica 31: 1-222.

Holman, J. (1981): One new and one little known Mediterranean Uroleucon species on Inula (Homoptera, Aphididae). - Acta Entomologica Bohemoslovaca 78: 43-52.

Holman, J. (2009): Host plant catalog of aphids, Palaearctic region. - Springer Science + Business Media B.V., Berlin. 1216 pp. https://doi.org/10.1007/978-1-4020-8286-3

Ilharco, F. A. \& van Harten A. (1987): Systematics. Pp. 51-77. In: Minks, A. K. \& HarREWIJN, P. (eds): Aphids: their biology, natural enemies and control. - Elsevier Science Publishers, Amsterdam.

Kanturski, M. \& Barjadze, S. (2020): A new species of the aphid genus Uroleucon from Lebanon, with notes on the systematic positions of U. altaicum, U. bielawskii and U. mulgedii (Hemiptera: Aphididae). - Zootaxa 4853(4): 548-561. https://doi.org/10.11646/zootaxa.4853.4.4

Nieto Nafría, J. M. (2013): Fauna Europaea: Hemiptera, Aphidoidea. - Fauna Europaea version 2017.06, https://fauna-eu.org

Robinson, A. G. (1988): Two new species of Uroleucon (Homoptera: Aphididae) from Pennsylvania. - The Canadian Entomologist 120(6): 581-585. https://doi.org/10.4039/ Ent120581-6

Szelegiewicz, H. (1962): Materialien zur Kenntnis der Blattläuse (Homoptera, Aphididae) Bulgariens. - Annales Zoologici 20(7): 47-65.

The Plants List (2013): Version 1.1. Published on the internet. Available from: http://www. theplantlist.org/ [accessed 15 September 2020]

Received September 30, 2020, accepted February 8, 2021, published August 16, 2021 